\title{
Dos pavilhões às ruas: a âncora territorial da reforma psiquiátrica
}

\section{From pavilion to the streets: the territorial anchor of the psichiatric reform}

\author{
Breno Augusto Souto Maior Fontes ${ }^{1}$
}

FONTES, B. A S. M. Dos pavilhões às ruas: a âncora territorial da reforma psiquiátrica. Rev. Ter. Ocup. Univ. São Paulo, v. 19, n. 3, p. 183-192, set./dez. 2008.

RESUMO: Do pavilhão às ruas: o fato mais significativo deste novo marco regulatório é o reconhecimento de que o transtorno mental deve ser enfrentado com o apoio substancial das redes de sociabilidade existentes no cotidiano das pessoas em tratamento: familiares, vizinhos, associações, trabalho, igreja... Que, diante do fato de que o sofrimento psíquico tem por conseqüência o empobrecimento destes laços de sociabilidade, o esforço terapêutico também deve se concentrar na âncora territorial - base fundamental do tecido social - coordenando os esforços da prática terapêutica em cooperação direta com os familiares, com associações civis e comunitárias. Pessoas com sofrimento psíquico (re) constroem suas sociabilidades a partir dos campos de pertencimento em trajetórias as mais diversas, envolvendo âncoras institucionais e práticas inscritas em sociabilidades primárias, secundárias, na busca de apoio e solidariedade. Este artigo pretende inventariar estas práticas, construindo tipologias de apoio e suas inscrições em círculos sociais; é um esforço preliminar para análise de dados de pesquisa em andamento sobre redes e apoio social.

DESCRITORES: Reforma dos serviços de saúde. Saúde mental. Apoio social.

\footnotetext{
1. Professor Associado do Departamento de Ciências Sociais e do Programa de Pós Graduação em Sociologia da UFPE (Universidade Federal de Pernambuco). Coordenador do NUCEM (Núcleo de Cidadania) e Pesquisador do CNPq.

Endereço para correspondência: E-mail: brenofontes@gmail.com
} 
$\mathrm{E}$ m 2001 é sancionada a Lei n. 10.216, que institui uma série de procedimentos a serem obedecidos quando da atenção à saúde mental. Referido instrumento legal - seguido por uma série de outros, que instituem o marco regulatório da política de saúde mental no Brasil - é resultado de uma ampla mobilização de instituições diversas como profissionais de saúde, associações civis de pessoas com transtorno mental, de familiares, ONGs de promoção de direitos civis, entre outras. A principal bandeira de luta deste movimento diz respeito ao tratamento desumano dado às pessoas com transtorno mental, ao modelo asilar, tido por ineficaz e inclusive agravante das condições de vida das pessoas lá instaladas. Apoiados em ampla literatura acadêmica, a luta contra a "morte social" denunciada por Goffman (1996) tem por objetivo retirar os residentes dos asilos e devolvê-los ao convívio da sociedade, procedendo a uma terapêutica que se ancora em uma abordagem interdisciplinar com, participação direta e intensa da sociedade civil.

Do pavilhão às ruas: o fato mais significativo deste novo marco regulatório é o reconhecimento de que o transtorno mental deve ser enfrentado com o apoio substancial das redes de sociabilidade existentes no cotidiano das pessoas em tratamento: familiares, vizinhos, associações, trabalho, igreja... Que, diante do fato de que o sofrimento psíquico tem por conseqüência o empobrecimento destes laços de sociabilidade, o esforço terapêutico também deve se concentrar na âncora territorial - base fundamental do tecido social - coordenando os esforços da prática terapêutica em cooperação direta com os familiares, com associações civis e comunitárias.

Pessoas com sofrimento psíquico (re)constroem suas sociabilidades a partir dos campos de pertencimento em trajetórias as mais diversas, envolvendo âncoras institucionais e práticas inscritas em sociabilidades primárias, secundárias, na busca de apoio e solidariedade. Este artigo pretende inventariar estas práticas, construindo tipologias de apoio e suas inscrições em círculos sociais; é um esforço preliminar para análise de dados de pesquisa em andamento sobre redes e apoio social ${ }^{(1)}$.

\section{AS NOVAS PRÁTICAS TERAPÊUTICAS}

A reforma psiquiátrica é o resultado direto do movimen- to antimanicomial, com origem em diversos países, e fruto direto do debate acadêmico e de práticas dos profissionais da saúde mental. Com efeito, intelectuais de diversas nacionalidades e orientações disciplinares se insurgem contra o tratamento dispensado a loucura; em um primeiro momento, a denúncia contra os maus tratos, a negação dos direitos básicos do ser humano, violados quase que sem cerimônia nos manicômio e instituições de cuidados. Mas também se questiona fortemente a própria idéia de doença mental, já há muito objeto de apropriação saberes biologizantes, mas sempre inscrita em um campo relativamente obscuro e sem conclusões definitivas. O que se coloca, como fato concreto, é uma ausência de uma etiologia definitiva, de, como no caso de diversas doenças, de uma nosologia clara sobre sua natureza. Percebem os críticos que alguns transtornos mentais escapam fortemente à tentativa de enquadramento, que, mesmo admitindo-se alguns ingredientes de verdade neste discurso, há outros igualmente importantes que são desprezados.

Neste debate da década de 60 são também valorizadas questões ligadas a uma série de fatores inscritos diretamente da vida cotidiana destas pessoas: suas famílias, o bairro onde moram, suas redes de amizade, hábitos, comportamentos e atitudes diante da vida herdados de cosmologias inscritas em campos culturais específicos... Enfim, questões que definitivamente complexificam o problema da loucura, exigindo desta forma novas abordagens. Questões, consequentemente, que implicam em refletir sobre práticas terapêuticas que se estendam além dos procedimentos de medicalização - recurso fortemente utilizados a partir da década de 50 , quando descobertas importantes sobre os psicofármacos permitem a sua ampla utilização - ou daqueles mais antigos, pertencentes ao recorte da higiene moral dos hospícios, preconizada por Pinel.

Os críticos assinalam que o dano mais devastador do transtorno mental, a morte social, pode ser resultado destas práticas. Na tentativa, em um primeiro momento, de isolar do ambiente onde provavelmente se encontrariam as causas do sofrimento psíquico, aplicando ao paciente técnicas de higiene moral e reconstruindo hábitos saudáveis de vida, há o resultado do isolamento, da alienação cada vez mais intensa do cotidiano, e sua substituição por um universo disciplinar inscrito nos muros do hospício. O poder disciplinar se afirma de forma a mais contundente e cruel, reescreven-

\footnotetext{
(1) A partir de uma pesquisa empírica com usuários de CAPS de quatro cidades brasileiras (Recife-PE, Fortaleza-CE, São Lourenço-RS e São Leopoldo-RS) intentamos recuperar a atenção à saúde mental, centrando-se objetivamente nas seguintes questões: há efetivamente uma concertada entre os cuidados profissionais e as redes de sociabilidade? Como os usuários e seus familiares avaliam esta nova prática terapêutica? Pesquisa com financiamento da FACEPE (Fundação de Apoio a pesquisa do Estado de Pernambuco) e CNPq.
} 
do a biografia destas pessoas em décadas de isolamento e submissão a regras de um cotidiano que absolutamente se afasta irremediavelmente do convívio social.

A denúncia da terapêutica inaugurada no final do século XVIII por Pinel e ainda vigente em plena segunda metade do século XX se associa a outras práticas de violência contra as pessoas, sempre inscritas nesta lógica de poder, tão bem descrita por Foucault: da disciplina, do deslocamento do soberano, visível e localizável, para a quase invisibilidade da lógica disciplinar, que se instala nas instituições, nas mentes e nos corpos das pessoas - o biopoder. São os hospícios, mas também as prisões, as escolas, as fábricas, enfim, a lógica perversa da modernidade.

Qual o sentido, então, da ressignificação da loucura? Em um primeiro plano, a denúncia contra a violação dos direitos fundamentais da pessoa e da reafirmação dos princípios da cidadania. Associada a esta questão mais ampla, o novo olhar sobre a loucura, de como se classifica, manipula e trata o sofrimento psíquico. Neste sentido, a denúncia do poder psiquiátrico, do monopólio de um saber e de uma terapêutica que produziu efeitos devastadores. Da possibilidade de se abrir novas perspectivas para a leitura da loucura, da entrada de novas linguagens e discursos, e também de novas abordagens terapêuticas.

Coloca-se, então, como questão central, a de se fazer possível o enfrentamento da loucura com o mínimo de danos. Danos relativos à despessoalização - do quotidiano do louco sem direitos e inclusive desassujeitado juridicamente. E também danos relativos à (im)possibilidade de uma vida ordinária, com pessoas, afetos e sociabilidades cotidianas $^{(2)}$.

Para o caso brasileiro, estas duas questões fundamentais se traduzem em uma prática terapêutica que tem por pressupostos dois princípios: (a) o da abordagem multidisciplinar, onde o discurso do psiquiatra convive com as leituras do terapeuta ocupacional, do psicólogo, do pedagogo, do assistente social; (b) O componente da territorialidade, que significa o fato de as ações dos CAPS se inscreverem sempre em associação com as sociabilidades primária e secundária das pessoas sob sua atenção; que as famílias, os grupos de vizinhança, as associações de moradores, os grupos de apoio e outros devem ser parceiros dos CAPS nesta nova prática terapêutica.

\section{CAPITAL SOCIAL E REDES DE APOIO: SOBRE COMO AS SOCIABILIDADES SÃO CONSTRUIDAS NOS CÍRCULOS SOCIAIS DA LOUCURA}

Agora nosso foco de atenção se dirige para o exame mais detalhado destas práticas de sociabilidade, de como se constroem os círculos sociais da loucura. Expressão tomada emprestada de Simmel ${ }^{(3)}$, a noção de círculo social sugere uma complexa interação de múltiplas sociabilidades, localizadas em contextos institucionais diversos que incorporam o cotidiano - ou o lebenswelt - das pessoas com transtorno mental. Neste círculo social específico encontramos os campos de sociabilidade localizados nas redes de laços fortes - amizades, família, vizinhança - laços fracos - trabalho, associações, Igreja, o próprio espaço do CAPS - onde circulam as pessoas. Refiro-me não somente às pessoas com transtorno mental, mas também seus familiares e as pessoas mais diretamente ligadas (amigos, profissionais da saúde mental, grupos de auto-ajuda e membros de associações, entre outros).

Compreender esta nova prática de cuidados, portanto, significa incorporar outros ingredientes à determinação do estado de sanidade ${ }^{(4)}$. Há ainda muitas dúvidas sobre estes novos componentes, embora se admita o consenso de sua importância. Sob o rótulo de "determinantes sociais em Saúde", reconhece-se que fatores externos ao individuo e presentes em seu cotidiano, em hábitos de vida e em práticas de sociabilidade, são fundamentais. Estudos epidemiológicos há muito tempo vem demonstrando a relação estreita entre condições de trabalho, renda e moradia como importantes determinantes do estado de sanidade de populações. Recentemente, toda uma série de estudos também sinaliza para o fato de se considerar as sociabilidades, a forma como as pessoas mantêm e alimentam suas redes como uma importante variável na explicação da gênese do processo de adoecimento. Com efeito,

\footnotetext{
(2)A despessoalização é uma técnica de cuidado que procurar retirar do individuo sob cuidados do hospício quaisquer características individualizantes que possam lhe remeter ao cotidiano extra-muros. Da mesma forma, o desassujeitamento refere-se a práticas de enquadramento jurídico dos loucos, retirando-lhes cidadania e características de sujeitos de sua existência, ao proceder à destituição de seus direitos civis. Ver sobre o assunto Castel (1976), Foucault (2001), Foucault (2006).

(3) Simmel (1999).

(4) Para o caso de saúde mental, "he causes of mental illness are also to be regarded as determined by society and, indeed, specifically by the living conditions in the community. S a logical consequences of this fact, social strategies must be put into effect for the prevention and treatment of mental illness, not only on a regional level but also on the local level of the community and the neighborhood as well as the level of primary and secondary groups" Legewie (1986, p. 219).
} 
"Estudos vêm demonstrando que um dos principais mecanismos pelo qual as iniqüidades de renda produzem um impacto negativo na situação de saúde é o desgaste dos laços de coesão social, a debilidade das relações de solidariedade e confiança entre pessoas e grupos, que são fundamentais para a promoção e proteção da saúde individual e coletiva" (PELLEGRINO FILHO, 2007).

Estas novas sociabilidades se manifestam desde as práticas ancoradas nos indivíduos, na construção de suas redes primárias, até as práticas que se estruturam alcançando comunidades, com efeitos que se disseminam para um grupo social mais largo. São, da mesma forma que aquelas sociabilidades localizadas em processos interativos inter-individuais, fenômenos que remetem à idéia de redes sociais, conceito que, grosso modo, pretende explicar, para o nosso caso, determinações sociais de saúde que ultrapassam o status quo da pessoa (sua renda, escolaridade, tipo de trabalho, ou outros atributos que os epidemiologistas tradicionais vêm estudando na determinação do estado de sanidade). São campos que se inscrevem em um escopo que considera as relações e não os atributos como unidade de análise. Emblemático neste sentido é o conceito de capital social, "que tem tido de crescente relevância para a explicação de padrões de desigualdades na saúde em comunidades.," (BUUS, 2007, p. 82) Uma série de estudos vem demonstrando que comunidades que mantêm índices importantes de capital social são aquelas que enfrentam de forma mais eficaz as iniqüidades e conseqüentemente conseguem promover melhores condições de vida inclusive de saúde - a seus membros ${ }^{(5)}$.

O estoque de capital social disponível nas comunidades, portanto, seria o elemento potencializador de seu desenvolvimento - ao lado dos capitais humano e físico; este tipo de capital, diferentemente dos outros, seria estruturado a partir dos vínculos estabelecidos a partir das relações entre as pessoas ${ }^{(6)}$ seria, portanto função da natureza particular das redes sociais estruturadas, funcionais a seu desenvolvimento. Haveria também uma certa relação entre as redes sociais egocentradas (que instrumentaliza um tipo de solidariedade, fundado nos laços fortes) e o nível de organização comunitária, operado a partir de suas associações voluntárias. É o que chamo de sustentabilidade das organizações voluntárias. Inicialmente estruturadas a partir de ações voluntárias estabelecidas em uma comunidade para o empreendimento de práticas visando a produção de bens públicos, estas organizações construíam suas identidades a partir da idéia de comunidade, locais de conviviabilidade e de estabelecimento de laços de pertencimento, que se traduziam no esforço coletivo para a produção do bem estar. Outras formas de identidade não necessariamente ligadas a uma comunidade de base territorial também seriam estruturadas a partir de redes, formadoras de capital social. O que se traduzia no que Wuthnow (1998, p. 7) designa de envolvimento cívico, "participação em atividades sociais que tanto estabelece mediação entre cidadãos e o governo quanto provê meios para cidadãos perseguirem objetivos comuns com ou sem ajuda do governo". O que caracteriza, deste modo, uma associação voluntária é exatamente esta vinculação com uma prática que se consubstancia a partir de um estoque de capital social, que por sua vez depende de um padrão de estruturação de sociabilidade particular.

Como se pode perceber, todos os fatores acima são de ordem sociais. Para além, portanto, das questões de morbidade ligadas diretamente a causas de natureza orgânicofisiológicas, há uma série de questões que são consequencia direta dos padrões civilizatórios de um povo (como técnicas e procedimentos curativos, hábitos alimentares, cuidados de higiene e questões relativas a hábitos de vida saudável), ou de padrões de sociabilidade de indivíduos e grupos específicos. São os que a literatura define por Determinantes Sociais de Saúde:

"Os determinantes sociais de saúde (SDH) são condições sociais em que as pessoas vivem e trabalham, ou, as características sociais dentro das quais a vida transcorre. Os determinantes sociais de saúde apontam tanto para as características específicas do contexto social que afetam a saúde, como para a maneira com que as condições sociais traduzem esse impacto sobre a saúde"(7).

O estoque de capital social, portanto, é um importante elemento a considerar quando se analisa a saúde humana. A partir deste acervo de capital social os indivíduos podem ter acesso a informações, recorrer a ajuda de outras pessoas

\footnotetext{
(5) Consultar a respeito Field, John. Social Capital. London, Routledge, 2003; Veja também Fontes (2000).

${ }^{(6)}$ Conforme afirma Burt(1998, p. 7), "capital social é uma qualidade criada entre pessoas enquanto capital humano é uma qualidade dos indivíduos"

${ }^{(7)}$ COMISSÃO de Determinantes Sociais de Saúde. Rumo a um modelo conceitual para análise e ação sobre os determinantes sociais de saúde. Ensaio para apreciação da comissão de determinantes sociais de saúde. Rascunho. Brasília, 05 de maio de 205.
} 
FONTES, B. A. S. M. Dos pavilhões às ruas: a âncora territorial. Rev. Ter. Ocup. Univ. São Paulo, v. 19, n. 3, p. 183-192, set./dez. 2008.

para o caso de enfrentamento de doenças ou dificuldades de ordem geral ${ }^{(8)}$, e em se organizando, cobrar das autoridades públicas a inclusão na rede de atendimento e mais qualidade nos serviços.

Considerando que o principal efeito da existência de estoque de capital social seja o de mobilizar recursos, podemos, para fins de análise, recortar os diversos campos de sociabilidade segundo os tipos de apoio social, instrumentalizando a idéia de círculos sociais a partir dos recursos e dos campos de sociabilidade envolvidos. O Quadro 1 ensaia uma tentativa de discriminar tipos de apoio por padrões de sociabilidade.

Quadro 1 - Sobre os círculos sociais da loucura e os tipos de apoio social

\begin{tabular}{|c|c|c|}
\hline \multirow[b]{2}{*}{ TIPOS DE APOIO } & \multicolumn{2}{|c|}{ CIRCULOS SOCIAIS E REDES DE SOCIABILIDADE } \\
\hline & $\begin{array}{c}\text { Redes } \\
\text { Primarias }\end{array}$ & Redes Secundárias \\
\hline $\begin{array}{l}\text { Apoio emocional } \\
\text { Apoio instrumental ou material } \\
\text { Apoio afetivo } \\
\text { Compartilhamento em atividades cotidianas (festas, jogos, } \\
\text { interaçoes sociais diversas) }\end{array}$ & $\begin{array}{l}\text { Família } \\
\text { Amigos } \\
\text { Vizinhos }\end{array}$ & \\
\hline $\begin{array}{l}\text { Interação social positiva (práticas que produzem efeitos } \\
\text { positivos na auto-estima) }\end{array}$ & & Amigos de trabalho \\
\hline $\begin{array}{l}\text { Apoio emocional } \\
\text { Compartilhamento em atividades cotidianas (festas, jogos, } \\
\text { interaçoes sociais diversas) }\end{array}$ & & $\begin{array}{l}\text { Grupos religiosos (Igrejas, terreiros, grupos espíri- } \\
\text { tas) }\end{array}$ \\
\hline Informação & & Associações de Moradores, Grupos religiosos \\
\hline $\begin{array}{l}\text { Informação } \\
\text { Controle social das ações públicas e ações para o melhora- } \\
\text { mento dos serviços }\end{array}$ & & Associações de usuários CAPS \\
\hline $\begin{array}{l}\text { Conselhos e orientações } \\
\text { Controle social das ações públicas e ações para o melhora- } \\
\text { mento dos serviços }\end{array}$ & & Associações de pessoas com Transtorno Mental \\
\hline $\begin{array}{l}\text { Informação } \\
\text { Conselhos e orientações }\end{array}$ & & Grupos de Discussão e de relacionamento Internet \\
\hline $\begin{array}{l}\text { Informação } \\
\text { Conselhos e orientações } \\
\text { Controle social das ações públicas e ações para o melhora- } \\
\text { mento dos serviços }\end{array}$ & & $\begin{array}{l}\text { Grupos de Familiares das pessoas com transtorno } \\
\text { mental }\end{array}$ \\
\hline Apoio instrumental ou material & & Serviços Profissionais - redes de assistência \\
\hline
\end{tabular}

FONTE: Gotlieb (1985), Schwarzer (2005), Charbonneau (2002), Griep (2003), Chor (2001).

(8) Apoio que pode se traduzir desde o de natureza psicológica (conforto, escuta) até o relativamente a ajuda monetária para pagamento, por exemplo de, gastos com medicamentos. 
A idéia seria traçar, "a partir da estrutura e composição dos círculos sociais onde as populações com transtorno mental participam" (GOTLIEB, 1981), as relações, de um lado, entre os campos de sociabilidade vivenciados por estas populações e as práticas terapêuticas dos CAPS. Importante assinalar que o quadro abaixo descreve as possibilidades mais recorrentes de práticas de sociabilidade, o que não significa que sejam consideradas todas as possibilidades nem que os atores se valham do conjunto destas práticas. $\mathrm{O}$ que ocorre na realidade são arranjos que se particularizam por uma série de características das populações estudadas; arranjos que são função de fatores diversos: cultura política, trajetórias biográficas, características demográficas e socioeconômicas, entre outras ${ }^{(9)}$. Assim, este quadro servirá apenas de roteiro indicativo para a leitura dos dados recolhidos em nossa pesquisa empírica. E a nossa pesquisa, por se constituir de informantes não recolhidos aleatoriamente ${ }^{(10)}$, não representa o universo deste círculo social.

Importa também assinalar que em alguns casos indicam-se os efeitos positivos destas sociabilidades; em alguns casos, podem haver registros de situações onde as interações resultam em sofrimento. É o caso, por exemplo, de situações onde o ambiente familiar provoca o agravamento do quadro clínico, ou quando há um ambiente hostil, de discriminação e preconceito entre os vizinhos. $\mathrm{O}$ que significa que nem todo tipo de sociabilidade tem por resultado em apoio social e efeitos consequentemente benéficos para a pessoa com transtorno mental.

Cabem, finalmente, algumas considerações sobre a terminologia empregada nos tipos de apoio. Primeiramente, "apoio social é um sistema formado por relações formais e informais através do qual um indivíduo recebe ajuda emocional, cognitiva e material para enfrentar situações geradoras de estresse" (GRIEP, 2003, p. 14-15).

A combinação destes campos de sociabilidade, aliada a características especificas de circulação de recursos, vão definir a estrutura do capital social e a consequente capacidade de mobilizar recursos. Este campo de sociabilidade, no qual está inscrita a rede CAPS, é previsto como importante instrumento terapêutico. Há, com efeito, nos projetos terapêuticos dos CAPS, a previsão de uso de práticas em associação com as sociabilidades dos usuários.
Com efeito, "Quando uma pessoa è atendida em um Caps, ela tem acesso a varios recursos terapêticos:

Atendimento individual: prescricão de medicamentos, psicoterapia, orientacão;

Atendimento em grupo: oficinas terapêuticas, oficinas expressivas, oficinas geradoras de renda, oficinas de alfabetizacão, oficinas culturais, grupos terapêuticos, atividades esportivas, atividades de suporte social, grupos de leitura e debate, grupos de confecão de jornal

Atendimento para a família: atendimento nuclear e a grupos de familiares, atendimento individualizado a familiares, visitas domiciliares, atividades de ensino, atividades de lazer com familiares;

Atividades comunitárias: atividades desenvolvidas em conjunto com associacões de bairro e outras instituicões existentes na comunidade, que têm como objetivo as trocas sociais, a integracão do servico e do usuário com a família, a comunidade e a sociedade em geral. Essas atividades pode ser: festas comunitárias, caminhadas em com grupos da comunidade, participacão em eventos e grupos dos centros comunitários ;

Assembléias ou reuniões de Organizacão do Servico: a assembléia é um instrumento importante para o efetivo funcionamento dos Caps como um lugar de convivência. È uma atividade, preferenicalmente semanal, que reúne técnicos, usuários, familiares e outros convidados que juntos discutem, avaliam e propõem encaminhamentos para o servico. Discutemm-se os problemas e sugestões sobre a convivência, as atividades e a organizacão do Caps, ajudando a melhorar o atendimento oferecido"-Grifos nosso (BRASIL, 2004, p. 17).

Os CAPS, portanto, incorporam em seu projeto terapêutico a idéia de que é importante se associar com as sociabilidades de seus usuários, organizando uma prática onde haja uma complexa participação destes diversos campos. Aqui, entra em cena um outro importante ingrediente, a idéia do território, âncora espacial das sociabilidades e referência para a constituição das identidades e orientações de práticas de reprodução do cotidiano. O território, muito mais que o simples recorte do espaço a partir de um quadro de referência de símbolos construtivos (casas, praças, ruas, etc), remete a um campo de amarração das sociabilidades cotidianas, o lugar onde se vive, o lugar onde as pessoas se encontram. Incrustar-se

\footnotetext{
(9) Podemos também pensar essas combinações diversas a partir de modelos sistêmicos, como o faz Luhmann (1995, p. xviii): What we call madness is nothing more than the hyper-complexity of psychic systems that can no longer distinguish themselves from their environnment.

(10) Escolhemos os informantes reproduzindo a clientela de cada CAPS estudado, segundo sexo, idade, e tipo de diagnóstico provável (esquizofrenia, transtorno bipolar e depressão, sendo os casos mais frequentes).
} 
neste território, fazendo efetivamente parte dele, imiscuirse nas sociabilidades cotidianas destas pessoas parece ser a fórmula para efetivamente tornar com efeito a missão desta nova prática terapêutica.

Fórmula que, como percebemos, está cheia de dificuldades. Primeira, a própria trajetória do serviço CAPS. Diferentemente do PSF (Programa de Saúde da Família), que conta com os agentes comunitários de Saúde - profisisonais de apoio ao serviço de atenção básica oferecido plas Unidades de Saúde e que são, estes profissionais, recrutados na comunidade - os CAPS têm que se fazer presentes a partir de trabalho de profissionais que não são da comunidade que muitas vezes, de classe média, desconhecem completamente a lógica do cotidiano de comunidades de baixa renda, onde mora a maioria dos usuários CAPS.

Segunda dificuldade, a própria formação profissional. Não lhes são ensinados modos de trabalho que desconstruam a idéia de corpo enquanto objeto de intervenção, lugar de constituição dos saberes e portanto de monopólio das práticas. Não se ensina nas Universidades a incorporação dos saberes, a constituição de uma prática que leve em conta o corpo-sujeito. Há ainda uma outra dificuldade, relativamente à prática profissional: no campo psi, os diversos saberes não convivem simetricamente; o reino da psiquiatria subsume todos os outros ${ }^{(11)}$, que lhe parecem acessórios e até mesmo secundários. Se há uma diretriz de prática interdisciplinar e de atenção ancorada territorialmente, e se até entre os profissionais a luta pelo poder-saber se instala, percebe-se quão difícil as interlocuções necessárias a esta empreitada.

Situando-se por fora - no campo territorial e também no campo simbólico, pois pertencentes a universos absolutamente incomunicáveis - os profissionais CAPS têm que realizar um esforço relativamente considerável para cumprir as exigências de sua missão. Esforço que se dirige na tentativa de estabelecimento de canais de comunicação com os círculos sociais dos usuários CAPS, e desta forma instaurar um modelo de atenção à saúde mental com participação direta das sociabilidades cotidianas das pessoas com transtorno mental. Neste sentido, cabem algumas observações
Em primeiro lugar, o resgate da família. Visto muitas vezes como a principal causa ou agravante de transtornos mentais, o ambiente familiar neste novo modelo de atenção é central. Na família se encontram os principais recursos de apoio indispensáveis ao enfrentamento do sofrimento psiquico: apoio nos cuidados essenciais à manutenção de sanidade (higiene, alimentação, controle na administração dos medicamentos) em momentos de crise; apoio emocional (a escuta, o gesto amigo e de compreensão, o compartilhar do sofrimento). $\mathrm{O}$ ambiente familiar é a peça central para uma terapêutica que não se apóie no internamento. Mas a rotina familiar é profundamente alterada pela ocorrência de transtorno psíquico em um de seus membros: muitas vezes a pessoa contribui financeiramente e agora passa a ser mais um fardo; há o estigma a ser enfrentado, resultando muitas vezes em afastamento de pessoas não somente ligadas ao doente, mas aos familiares, de forma geral; e a própria natureza da doença não é percebida de forma clara, ocasionando perplexidades e dificuldades na lida. Duarte descreve algumas das situações mais típicas a serem enfrentadas pelos serviços CAPS relativamente à consideração da familia enquanto parte importante da terapêutica:

“A presença de uma pessoa que sofre de um transtorno mental produz alterações no seio da família. antes da doença, a pessoa tinha condições de contribuir não só financeiramente, mas nas atividades domésticas e responsabilidades. Quando ocorre a modificação no comportamento dessa pessoa, há modificações da rotina familiar, porque se sente a falta da ajuda que era compartilhada e ainda arca-se com a responsabilidade de ajudar a pessoa doente.

Liberman $(1998)^{(12)}$ acrescente como custos emocionais para os membros da família a ansiedade e tensão, a culpa, a desmoralização e depressão, o desgosto e a frustração, assim além das repercussões no estado clínico. Relata o aparecimento frequente de sintomas psiquiátricos nos familiares. Elsen $\left(1994^{a}\right)^{(13)}$ afirma ser um desafio para os serviços de saúde "cuidar de quem cuida", ou seja, ir de encontro da família, conhecendo como cuida, identificando suas dificuldades e suas forças para melhor atuação profissional, através do conhecimento das necessidades familiares". (DUARTE, 2007, p. 35).

\footnotetext{
(11) o que Foucault(2006, p. 164) chama de poder psiquiátrico: "no meio das suas relações com o louco, em vez de fazer o problema da verdade irromper no choque entre médico e doente, o poder psiquiátrico coloca a questão da verdade somente no interior dele próprio. Ele faz de saída e de uma vez por todas, constituindo-se como ciência médica e clínica. Ou seja, em vez de estar em jogo na cura, o problema da verdade foi resolvido de uma vez por todas pela prática psiquiátrica, a partir do momento em que ela se deu como estatuto ser uma prática médica e como fundamento ser uma aplicação de uma ciência psiquiátrica.

${ }^{(12)}$ Liberman. Psychiatric rehabilitation of chronic mental patients. Washington, DC: American Psychiatric Press, 1988.

${ }^{(13)}$ Elsen. Desafios da enfermagem no cuidade de famílias. In: Bulb, (coord) Marcos para a prática de enfermagem com familias. Florianópolis: Ed. da UFSC, 1994.
} 
Há também que considerar o fato de que em muitos casos a estrutura familiar é profundamente desorganizada, não sendo raro encontrar em seu seio muitas pessoas com problemas: alcoolismo, desemprego e carências as mais diversas decorrentes do estado de pobreza ${ }^{(14)}$. O que agrava substancialmente o quadro de recuperação da pessoa a ser tratada, significando em muitos casos que não somente aquele que é usuário CAPS deve ser tratado, mas toda a sua familia. $\mathrm{O}$ ambiente familiar é indispensável para a manutenção da pessoa com transtorno mental fora dos manimômios, em muitos casos. Mas também há um número importante destas familias que têm dificuldades sérias o suficiente que as impedem de prestar a estas pessoas um apoio adequado. $\mathrm{O}$ que faz com que alguns autores assinalem um risco importante da reforma psiquiátrica ${ }^{(15)}$, a desasssistência, decorrente do desengajamento do Estado de suas funções constitucionais.

Um outro campo também muito importante são as associações inscritas neste círculo social da loucura acima detalhado. Os campos de sociabilidade secundária têm por característica fundamental o fato de que os vinculos estabelecidos entre os participantes são de natureza diversa daqueles resultantes das sociabildiades primárias: os contatos não se fazem de forma initerrupta, ao longo do tempo, os laços estabelecidos são em sua maioria caracteristicamente pontuais e mediados por objetivos específicos; não se verifica, ao contrário dos resultantes das sociabilidades primárias, intensidade afetiva e motivações difusas. Os participantes destas sociabilidades têm objetivos comuns a alcançar que, em alguns casos, não poderiam ser obtidos com esforços isolados. O conteúdo associativo se revela, desta forma, em sua característica mais fundamental, no fato de que os recursos são alocados coletivamente, resultantes do esforço organizativo de uma comunidade de interesse. Isto é válido para fenômenos que vão desde os comportamentos religioso e político até os de natureza lúdico-recreativa.

Ingrediente fundamental neste círculo social da loucura, as práticas associativas podem se constituir em poderoso auxiliar no enfrentamento do transtorno mental, tanto pelos que sofrem quanto pelos que cuidam e convivem de perto. Conforme verificamos no Quadro 1, recursos de apoio como informação, controle social, apoio material estão presentes nestas práticas de sociabilidade. São, na maior parte dos casos, partes da vida cotidiana, quase que "naturais". Para alguns recursos ou modalidades especificas, entretanto, requerem toda uma série de requisitos amplamente descritos por "capital político" ou "cultura cívica", que muitas vezes são inexistentes em comunidades de baixa renda: capacidade de reconhecer e fazer valer seus direitos, experiências concretas - a partir de trajetórias de socialização política funcionais à participação política - que indicam consciência de direitos e de cidadania, inexistentes em sociedades com presença de fortes desigualdades sociais, assimmetria que se reflete também nas práticas políticas de seus membros.

É o que acontece entre os estudados. A regra geral é a existência de uma fraca densidade associativa - pelo menos aquela que se traduz em mobilização por recursos publicos - o que de imediato se traduz na inexistência de um requisito fundamental para o funcionamento do modelo CAPS: os parceiros na comunidade que se associariam aos técnicos no empreendimento de ações terapêuticas. Assim, em muitas vezes, quando se encontram ações exitosas, tal fato é resultado de iniciativa de um técnico que promove o surgimento ou revigoramento de associações, com intervenções contínuas e intensas na comunidade ${ }^{(16)}$.

Como percebemos, o modelo CAPS pressupõe muito mais que uma legislação adequada e uma infra-estrutura organizacional. Há toda uma série de ingredientes que muitas vezes escapam à vontade do agente público:

\footnotetext{
(14) não é incomum encontrar depoimentos de cuidadores - membros da família que se ocupam diretamente dos usuários CAPS - argumentarem que os cuidados dispensados em hospitais psiquiátricos devem ser reativados, que a forma mais adequada de tratamento destas pessoas é o internamento. Argumentam que lá são alimentadas, a medicação é administrada mais eficazmente e também que não perturba os que têm que trabalhar e cuidar de suas vidas.

(15) alguns autores, inclusive, assinalam que a reforma psiquiátrica é resultado de políticas de redução dos altos custos dos procedimentos tradicionais. Esta é, por exemplo, a opinião de Valastro (2001): Les facteurs économiques ont joué un rôle central dans ce processus : les lieux d'enfermement et les hôpitaux psychiatriques étaient trop côteux. L'économie a exercé un influence redoutable sur le processus de fermeture des hôpitaux psychiatriques, une loi financière a fait davantage que les interventions pour une psychiatrie avec un modèle de traitement territoriale de la santé mentale. La crise du welfare state n'a pas épargné la psychiatrie : le fléchissement des ressources a affermi le principe de la reforme de l'administration publique, avec la reconnaissance de partenaires et d'acteurs extérieures dans le traitement de la souffrance et de l'intervention dans le champ de la santé mentale.

(16) Não quero dizer que inexista por completo associações presentes no círculo social da loucura. A realidade mostra que, como nos casos relativamente à organização comunitária de forma geral, a pobreza e as carências as mais diversas também se estendem para a capacidade organizativa: carentes de recursos materiais são na maior parte dos casos também carentes de cultura cívica.
} 
mesmo empenhado seriamente em conduzir práticas terapêuticas ancoradas territorialmente, esta base territorial está fragmentada, desorganizada e pobre relativamente à capacidade associativa. Pobreza que reflete o estado geral de carência de uma população, excluída e marginalizada não somente pela loucura dos seus, mas pela incapacidade mais ampla de a sociedade gerar oportunidades e condições dignas de vida. Não obstante esta constatação geral, encontramos relatos riquíssimos de experiências exitosas, práticas que misturam vontade política dos gestores e técnicos, atores da sociedade civil atuantes e cidadãos ciosos de seus direitos. Os dois exemplos - ausência completa de densidade associativa ou exuberância destas práticas - são é claro extremos; a realidade se forma a partir de pontos localizadados em um amplo gradiente de possibilidades que são o resultado da combinação particular das sociabilidades dos atores diversos presentes no que chamei "círculo social da loucura".

FONTES, B. A S. M. From pavilion to the streets: the territorial anchor of the psichiatric reform.

Rev. Ter. Ocup. Univ. São Paulo, v. 19, n. 3, p. 183-192, set./dez. 2008.

\begin{abstract}
From pavilion to the streets: the most significant fact of this new system is the acknowledgment that mental health care must be faced with the support of social networks from quotidian life of people with mental disorders: family members, neighbors, civil associations, workmates, religion institutions... Concerning the fact that the psychic suffering has as important consequence the impoverishment of the social ties; the therapeutic effort also has to concentrate in the territorial anchor - fundamental basis of social network - in direct cooperation between the therapeutic practice and family, civil and communitarian associations. People with psychic suffering (re)build their sociability in belonging scenarios with the most diverse trajectories, implicating institutional anchors and practice of primary and secondary sociability, seeking for support and solidarity. Este artigo pretende inventariar estas práticas, construindo tipologias de apoio e suas inscrições em círculos sociais; é um esforço preliminar para análise de dados de pesquisa em andamento sobre redes e apoio social. This article intends to investigate these practices, building support typologies and their inscriptions in social circles; it is a preliminary effort of analyzing research data about network and social support, still in progress.
\end{abstract}

KEY WORDS: Health care reform. Mental health. Social support.

\title{
REFERÊNCIAS
}

BRASIL, Ministério da Saúde. Secretaria de Atencão à Saúde. Departamento de acões Programáticas estragégicas. Saúde Mental no SUS: os centros de atencão psicosocial/Ministério da Saúde, Secretaria de Atencão à Saúde, Departamento de Acões Programáticas Estratégicas. Brasília: Ministério da Saúde, 2004.

BURT, R. The gender of social capital. Rationality and Society, v. 10, n. 1, p. 5-46, 1998.

BUSS, P. M.; PELLEGRINI FILHO, A. A saúde e os determinantes sociais. PHYSIS. Rev. Saude Coletiva, Rio de Janeiro, v. 17, n. 1, p. 77-93, 2007.

CASTEL, R. L'ordre Psychiatrique. L'âge d'or de l'aliénisme. Paris: Ed. de Minuit, 1976.

COMISSÃO DE DETERMINANTES SOCIAIS DE SAÚDE. Rumo a um modelo conceitual para análise e ação sobre os determinantes sociais de saúde. Ensaio para apreciação da comissão de determinantes sociais de saúde. Rascunho. Brasília, 2005.

DUARTE, M. de L. C. Avaliação da atenção aos familiares num centro de atenção psicossocial: uma abordagem qualitativa. Dissertação (Mestrado) - Escola de Enfermagem de Ribeirão Preto - Universidade de São Paulo, 2007.

ELSEN Desafios da enfermagem no cuidado de famílias. in BULB, (coord.). Marcos para a prática de enfermagem com familias. Florianópolis: Ed. da UFSC, 1994.

FIELD, J. Social capital. London: Routledge, 2003.

FONTES, B. A. S. M. Capital social e terceiro setor: sobre a estruturação das redes sociais em Associacões voluntarias. Rev. CRH, Salvador, v. 30/31, p. 239-264, 2000.

FOUCAULT, M. O poder psiquiátrico. São Paulo: Martins Fontes, 2006.

FOUCAULT, M. Le pouvoir psiquiatrique. In: Foucaut, M. Dits et Écrits, v I. Paris: Gallimard, 2001. p. 1543-1554.

GOFFMAN, E. Manicômios, prisões e conventos. São Paulo: Perspectiva, 1996. 
FONTES, B. A. S. M. Dos pavilhões às ruas: a âncora territorial. Rev. Ter. Ocup. Univ. São Paulo, v. 19, n. 3, p. 183-192, set./dez. 2008.

GOTTLIEB, B. H, ed. Social networks and social support. London: Sage Publications, 1981. (Sage Studies in community mental health, 4).

GRIEP GRIEP, R. H. Confiabilidade e validade de instrumentos de medida de rede social e de apoio social utilizados no estudo pró-:saúde. Rio de Janeiro, 2003. Tese (doutorado) - Fundação Oswaldo Cruz, Escola Nacional de Saúde Pública.

LEGEWIE, H.; WIEDERMANN, P. M. Part E: mental health introduction. In: FRICK, D. (Ed.) The quality of urban life. Social, psychological and physical conditions. Berlin: Walter de Gruyter, 1986. p. 219-227.

LIBERMAN. Psychiatric rehabilitation of chronic mental patients. Washington, DC: American Psychiatric Press, 1988.

LUHHMAN, N. Social systems. Stanford, CA: Stanford University Press, 1995.

PELLEGRINO FILHO, A. Compromisso com a ação. Secretaria técnica da Comissão Nacional sobre os determinantes sociais da saúde (CNDSS), HTTP://www.determinantes.fiocruz.br/ compromissoscomacao.htm. (consultado na Internet em 05 de janeiro de 2007.

SIMMEL, G. Sociologie. Etude des formes de socialisation. Paris, PUF, 1999.

SOUZA, R. C.; SCATENA, M. C. M.. Producão de sentidos acerca da família que convive com o doente mental. Rev. Latino-Am Enfermagem, v. 13, n. 2, p. 73-9, 2005.

VALASTRO, O. M. De l'enfermement au territoire: réseaux sociaux et enjeux nouveaux Revue électronique de sociologie, $\mathrm{v}$. 03(4) http://critique.ovh.org Acesso em 06 de junho de 2006.

WUTHNOW, Robert. Loose connections. joining together in America's fragmented communities. Cambridge, MA: Harvard Unversity Press. 1998. 